\title{
GESTÃO MERCADOLÓGICA E LUCRATIVIDADE: UM ESTUDO COM JOGOS DE EMPRESAS
}

\author{
MARKETING MANAGEMENT AND \\ PROFITABILITY: A STUDY WITH BUSINESS \\ GAMES
}

Recebido 19/10/2011

Aceito $10 / 12 / 2011$

Marco Antônio Silva ${ }^{1}$

Antonio Carlos Aidar Sauaia ${ }^{2}$

\section{RESUMO}

\begin{abstract}
A gestão mercadológica é fundamental nas organizações por afetar a geração de receitas. Todavia, os gestores pouco têm compreendido o impacto dessa gestão na lucratividade, face à dificuldade de mensuração dos efeitos sobre os resultados. Neste estudo, comparou-se a gestão mercadológica em empresas que atuaram com foco operacional ou com foco estratégico. Num jogo de empresas com nove concorrentes, averiguaram-se descritivamente alguns efeitos da administração mercadológica sobre o lucro e a taxa interna de retorno. A análise das decisões evidenciou que quatro empresas agiram com foco operacional e que cinco empresas agiram com foco estratégico. Os resultados mostraram que a gestão com foco estratégico absorveu investimentos maiores, o que gerou maior valor aos acionistas, mantendo a expectativa de continuidade do negócio. Os jogos de empresas como ambiente de pesquisa têm muito a contribuir para os estudos empíricos na área de Marketing.

Palavras-Chave Gestão de mercado; Gestão estratégica; Gestão operacional; Lucratividade; Jogos de empresas.
\end{abstract}

\footnotetext{
${ }^{1}$ Doutorando em Administração na Faculdade de Economia, Administração e Contabilidade da Universidade de São Paulo - FEA/USP, Professor de Finanças da Pontifícia Universidade Católica de São Paulo - PUC/SP e da Escola Superior de Propaganda e Marketing - ESPM, São Paulo - SP, Brasil. E-mail: marcothe@gvmail.br

${ }^{2}$ Professor Associado - Livre Docente - Faculdade de Economia, Administração e Contabilidade da Universidade de São Paulo - FEA/USP, São Paulo - SP, Brasil. E-mail: asauaia@usp.br
} 


\section{ABSTRACT}

The marketing management in organizations is crucial for affecting the generation of revenue. However, managers have little understood the impact of management on profitability, because the difficulty of measuring the effects on the results. This study compared marketing management in companies that worked with operational focus to those working with strategic focus. Data produced in a business game with nine competing firms were examined in a descriptive study focusing the impact on profits and on the Internal Rate of Return. The analysis of the decisions revealed that four companies were operational oriented and five companies were strategic oriented. The results showed that the strategic marketing management absorbed larger investments, generating greater value to shareholders and maintaining the expectation of business continuity. Business games as a research environment have much to contribute to empirical studies in the Marketing field.

Keywords Marketing management; Strategic marketing management; Operational marketing management; Profitability; Business games.

\section{INTRODUÇÃO}

A área de marketing é politicamente muito forte dentro das organizações, porque é a principal fonte de receitas (SCHMIDT, SANTOS, KLOECKNER, 2006, p. 8). No entanto, é uma das funções menos compreendidas e de difícil mensuração em muitas empresas. Esta incompreensão se dá em grande parte porque as consequências das decisões tomadas nessa área são difíceis de quantificar em termos de impacto sobre o resultado da empresa, como o gerenciamento de produto, o incremento dos gastos em propaganda, a pesquisa e desenvolvimento e a redução no preço de venda (FERRIS e outros, 2007, p. xi).

Nesse contexto, os profissionais de marketing elaboram estratégias e tomam decisões fundamentadas na avaliação da empresa, na análise da concorrência e do comportamento do consumidor. $\mathrm{O}$ desafio desses profissionais é gerenciar o composto de marketing, popularizado pelos 4Ps - produto, preço, promoção e praça -, para alcançar os objetivos das organizações (CHURCHILL, 2005, p. 20).

Para tal fim, alguns consideram que as decisões relativas ao composto de marketing ideal são aquelas que maximizam a satisfação para o cliente. Outros tentam abordar o problema declarando que o objetivo é elaborar um composto de marketing que dê satisfação ao cliente com lucro para a empresa e que maximize o valor para o acionista, visto que o desequilíbrio entre essas visões gera investimentos excessivos e margens inadequadas, vindo a comprometer a viabilidade empresarial (NAGLE, HOLDEN, 2002, p. 1) Em decorrência, os gerentes têm dado maior atenção ao impacto financeiro das estratégias de marketing. Essa prática, embora desafiadora para as empresas, é condizente com a orientação para marketing. A capacidade da empresa de atender as necessidades e os desejos dos clientes deve gerar resultados para a organização. O retorno do investimento pode garantir a continuidade dos fluxos de receitas e lucro, além de estabelecer o limite até onde a organização pode ir para atender o consumidor (URDAN, URDAN, 2006, p. 16).

Para Aaker, (1992, p.11-12), o reconhecimento das demandas de um ambiente de negócios de rápidas mudanças tem estimulado o desenvolvimento de métodos e sistemas de resposta imediata, em particular, a necessidade de um sistema de informação em tempo real e contínuo em lugar de uma simples análise periódica. A gestão estratégica de mercado serve para enfatizar a necessidade de desenvolver estratégias adaptativas voltadas para o mercado. Esta serve também para sublinhar o fato de que o processo deve ser proativo e não reativo com o objetivo de influenciar o ambiente externo, além de simplesmente responder a mudanças. 
Assim, tanto profissionais de marketing como pesquisadores buscam referências amplas e prática com base científica para uma gestão eficaz das estratégias de marketing, visando quantificar seus resultados. Em decorrência, o objetivo desta pesquisa foi verificar, num Laboratório de Gestão, se a administração estratégica de marketing, nas empresas estudadas, promoveu lucros contínuos e gerou valor para o acionista. A seguir, este artigo está estruturado nas seguintes seções: revisão da literatura, problema de pesquisa, método de pesquisa, descrição do experimento e coleta de dados, análise descritiva dos dados, discussão dos resultados, conclusões, limitações e pesquisas futuras.

\section{REVISÃO DA LITERATURA}

O referencial teórico que fundamenta este artigo desdobra-se em três pilares conceituais, a saber: 1) gestão de mercado; 2) composto mercadológico e; 3) lucratividade e retorno nas empresas.

\subsection{Gestão mercadológica}

O marketing é uma função gerencial, que busca ajustar a oferta da organização e as demandas específicas do mercado, utilizando como ferramental um conjunto de princípios e técnicas (ROCHA, CHRISTENSEN, 1999, p. 15). Conforme a definição da American Marketing Association (2004), marketing é o processo de planejar e executar a determinação do preço, a promoção e a distribuição de idéias, de produtos e serviços para criar trocas entre indivíduos e organizações. Para Lilien e Rangaswamy (2002, p.1), marketing é um processo societal e gerencial, pelo qual as trocas são realizadas para satisfazer as necessidades e os desejos dos indivíduos e das organizações.

Urdan e Urdan (2006, p. 5-6) relatam que a definição de marketing como troca é complementada pelo significado de marketing como filosofia organizacional e processo. No sentido filosófico, é um princípio organizacional que ressalta as necessidades do cliente, a integração das áreas em função do mercado e a geração de lucro decorrente da satisfação dos clientes. Como processo, compreende um conjunto de atividades executadas logicamente para alcançar resultados, ou seja, realizar trocas, gerar valor e atender os objetivos da empresa.

Para a consecução dos objetivos empresariais, Urdan e Urdan (2006, p. 25) ainda ressaltam que os gerentes tomam decisões estratégicas e tático-operacionais. Uma decisão é estratégica quando encerra implicações de longo prazo, não é revertida com facilidade, consome recursos elevados, compreende diversas áreas funcionais da empresa, tem potencial de modificar a competitividade do negócio e pode afetar a continuidade e os resultados futuros da organização. Adicionalmente, conforme ressalta Diniz e Castro (2010, p. 315), se faz necessário o alinhamento entre as instâncias estratégicas e operacionais da empresa. Assim, é imprescindível alocar os recursos, ajustar a estrutura, os processos e as pessoas, pois estes são fatores que, por certo, influenciarão a execução da estratégia para se atingir os objetivos organizacionais.

A gestão estratégica de mercado é fundamentada no princípio de que o ciclo de planejamento operacional é inadequado para lidar com a alta taxa de mudança que pode ocorrer no ambiente de atuação da empresa. Para lidar com as ameaças e oportunidades que surgem rapidamente nesse cenário, as decisões estratégicas precisam ser antecipadas e tomadas fora do ciclo de planejamento operacional (AAKER, 1992, p. 11-12). Partindo-se do exame das necessidades dos indivíduos e das organizações, a função do marketing estratégico 
é seguir a evolução do mercado de referência e identificar os diferentes produtos-mercado (produtos cuja atratividade é necessário que se avalie) e os segmentos atuais ou potenciais, na base da análise da diversidade de necessidades a satisfazer (LAMBIN, 2000, p. 9).

A função do marketing estratégico é nortear a empresa para as oportunidades existentes ou criar oportunidades atrativas adequadas aos seus recursos, oferecendo um potencial de crescimento e rentabilidade. A dimensão temporal situa-se no médio e longo prazo e o seu objetivo específico é definir metas, elaborar uma estratégia de desenvolvimento e cuidar da manutenção de uma estrutura equilibrada da carteira de produtos (LAMBIN, 2000, p. 10). Apesar da difícil compreensão e previsão do ambiente de negócios, Aaker (1992, p. 16) ressalta as vantagens da gestão estratégia do mercado:

1) Antecipar a avaliação da escolhas estratégicas;

2) Forçar uma visão de longo prazo;

3) Visualizar a decisão de alocar recursos;

4) Auxiliar a análise estratégica e a tomada de decisão;

5) Propiciar um sistema de controle e gerenciamento estratégico;

6) Promover a comunicação horizontal e vertical e sistemas de coordenação;

7) Auxiliar um negócio a lidar com mudanças.

Por outro lado, o marketing operacional, conforme Lambin (2000, p. 7-8), caracteriza a ação no conceito de marketing. Quando praticado, revela um comportamento voluntarista de conquista de mercados existentes, cujo horizonte de ação se situa no curto/médio prazo. Representa o típico comportamento comercial, orientado para o volume de vendas e ancorado nos meios táticos retirados da política de produto, da distribuição, do preço e da propaganda. A função do marketing operacional é gerar volume de negócios utilizando os meios eficazes de vendas e comunicação sem esquecer a minimização dos custos de vendas.

Tradicionalmente, conforme ressalta Cova $(2008$, p.4), o marketing esteve focado nos seus aspectos tradicionais como o desenvolvimento de produtos, a realização de atividades promocionais e a busca de preços competitivos. No Quadro 1, comparam-se as funções do marketing operacional com as do marketing estratégico.

\begin{tabular}{|l|l|}
\hline \multicolumn{1}{|c|}{ Marketing Operacional } & \multicolumn{1}{c|}{ Marketing Estratégico } \\
\hline Abordagem voluntarista & Abordagem de análise \\
\hline Explorar oportunidades existentes & Identificar novas oportunidades \\
\hline Meios: preço, publicidade, venda, promoção & Meios: escolha de produtos-mercado \\
\hline Comportamento reativo & Comportamento pró-ativo \\
\hline Horizonte: curto prazo & Horizonte: médio-longo prazo \\
\hline Responsabilidade da função marketing & Responsabilidade interfuncional \\
\hline
\end{tabular}

Quadro 1 - Marketing operacional vs Marketing estratégico. Fonte: LAMBIN, 2000, p. 10.

Portanto, o conceito de marketing estratégico pode ser entendido como a função empresarial que cria valor para o cliente e que gera vantagem competitiva duradoura para a empresa. Para esse fim, o gerente de marketing utiliza um conjunto de variáveis controláveis - produto, preço, comunicação e distribuição -, por meio das quais ele pode obter o melhor ajustamento entre a oferta de sua empresa e a demanda existente (ROCHA, CHRISTENSEN, 1999, p. 26). Esse conjunto de variáveis, denominado composto de marketing, será tratado na seção a seguir. 


\subsection{Composto mercadológico}

Profissionais e acadêmicos norte-americanos difundiram, em meados de 1960, a expressão composto de marketing ou 4Ps referindo-se às variáveis: produto, praça (distribuição), preço e promoção (URDAN, URDAN, 2006, p. 28). As decisões sobre o composto mercadológico devem ser tomadas para que exerçam influência sobre os canais comerciais e sobre o consumidor (KOTLER, KELLER, 2006, p. 17). Para a maioria dos profissionais de marketing, o composto mercadológico é elaborado para atender às necessidades e aos desejos dos clientes. Dentro dessa visão, Lauterbon (1990) articulou o conceito dos quatro Cs - uma solução para o cliente, custo para o cliente, conveniência e comunicação. A função dos quatro Ps é corresponder a cada um desses Cs (Solução para o cliente - Produto; Custo para o cliente - Preço; Comunicação - Promoção; Conveniência - Praça). Assim, um composto eficaz é aquele que oferece um produto que: a) atende o cliente com baixo custo; b) comunica eficientemente os benefícios e c) pode ser adquirido com extrema conveniência.

Segundo Doyle (2005, p. 204) a limitação dessa visão estritamente sobre o composto de marketing é que não avalia o sentido econômico para a empresa. Embora maximize o valor para os clientes, pode minimizar o valor para os acionistas. Por exemplo, o produto que dá a melhor solução para um cliente provavelmente é o produto que agrega valor (benefícios específicos) para aquele cliente. Para a empresa, isso poderia demandar uma linha de produto muito ampla com altos custos de produção e elevados investimentos.

Para atender as necessidades dos consumidores, as empresas têm que ponderar uma série de fatores na deliberação sobre o composto mercadológico e suas ofertas. Conforme Werneck e Cruz (2009, p. 4), as firmas devem desenvolver um mix de marketing de modo a satisfazer às necessidades de mercados-alvo e, ao mesmo tempo, atingir os objetivos de marketing da organização. Segundo Dias (2006, p. 9), a gestão das variáveis mercadológicas compreende as seguintes decisões:

- As decisões de produto englobam a identificação de oportunidades de lançamento de produtos e serviços, a adequação destes às necessidades e aos desejos dos clientes, a formulação das estratégias de produtos (como diferenciação, posicionamento) e a administração do ciclo de vida do produto.

- As decisões de preço envolvem a determinação de estratégias de preço que geram vantagem competitiva e diferenciação para cada produto ou linha de produto, bem como maximizam retorno para a empresa.

- As decisões de promoção são aquelas relativas aos investimentos em estratégias e atividades de comunicação (propaganda, marketing direto, relações públicas, publicidade, eventos, seminários) e em promoção de vendas (sorteios, prêmios ao consumidor, descontos de preço, brindes e outros).

- As decisões da variável distribuição englobam a escolha dos canais de vendas e distribuição para que o produto esteja no lugar certo, no momento certo, e o cliente possa realizar a compra e satisfazer a sua necessidade.

Com base nessas decisões, o gerenciamento do composto de marketing exige esforços coordenados e eficazes para a obtenção dos objetivos da organização. A empresa pode alterar seu preço, sua força de vendas e suas despesas com propaganda no curto prazo. Mas só pode desenvolver novos produtos e modificar seus canais de distribuição no longo prazo (KOTLER, KELLER, 2006, p.17) 
Doyle (2005, p. 204), entretanto, adverte que os consumidores buscam custos baixos, o que, em muitas situações, significa lhes oferecer preços menores. Já a conveniência e a comunicação dos benefícios dos produtos oferecidos pelas empresas envolvem custos e investimentos mais altos. A combinação preços baixos, altos custos operacionais e alto investimento em promoção e em distribuição, geralmente, não resulta na continuidade do negócio.

Todavia, diante dessa incompatibilidade, Dias $(2006$, p. 9) ressalta que, através da gestão do composto mercadológico, as empresas devem otimizar o valor para o cliente e, concomitantemente, para o acionista. Apesar de muitos profissionais não acreditarem na possibilidade de se atingir um ponto de equilíbrio entre esses dois objetivos, o crescimento e a lucratividade da empresa de forma contínua dependem desse equilíbrio. Além disso, o lucro e o retorno sobre o investimento realizado representam a recompensa dos acionistas pelos riscos assumidos por alocarem capital na atividade empresarial.

\subsection{Lucratividade e retorno nas empresas}

Segundo Doyle (2005, p. 206-7), os profissionais de marketing precisam estar conscientes da importância do lucro e devem tomar decisões que proporcionem valor para o acionista. Os principais argumentos em favor do gerenciamento do valor são: 1 ) direito de propriedade - as empresas são de propriedade de seus acionistas, e a administração deve maximizar o valor para eles e fazer isso com integridade; 2 ) o mercado de capitais - os executivos não conservarão seus empregos se os acionistas não acreditarem que os gestores estão seguindo estratégias para criar valor; 3) os stakeholders - uma empresa que busca maximizar o valor para o acionista não pode negligenciar clientes, trabalhadores, governo e sociedade, o que é essencial para a continuidade do negócio; 4) foco no desempenho de longo prazo - mudanças nos lucros em curto prazo causam pouco impacto sobre o valor para o acionista. Os primeiros cinco anos de lucro e fluxos de caixa raramente correspondem a mais do que um terço do valor da empresa; e 5) princípios racionais e intelectuais - sem uma estrutura racional é impossível desenvolver uma estrutura para otimizar as decisões sobre o composto mercadológico e o valor para o acionista de maneira precisa e racional.

Monroe (2003, p. 31) ressalta que, para tal fim, na prática, as empresas podem auferir seus resultados de diferentes maneiras. Geralmente, utilizam medições alternativas de lucro, estabelecendo seus ganhos não em termos de valor absoluto, mas sob a forma de uma razão, tais como margem de contribuição por unidade vendida, lucro por volume de vendas, rendimento por ação, retorno sobre os ativos, retorno sobre o investimento, retorno sobre o patrimônio ou mesmo sobre os estoques.

Esse resultado é traduzido na forma de lucratividade. Segundo McGuigan e outros (2004, p. 6), o lucro é a diferença entre a receita total e o custo total. A receita é proveniente do preço estabelecido pela empresa multiplicada pela quantidade vendida. $O$ custo de qualquer atividade pode ser considerado como a oportunidade alternativa de valor da qual se abre mão. A fim de atrair recursos econômicos para suas atividades, as firmas pagam um preço por fatores (mão de obra, capital e recursos naturais) que convençam os detentores desses recursos a sacrificar alternativas e a direcionar os recursos para essa utilização.

Os administradores devem conduzir as empresas de modo a gerar valor para os acionistas. Para esse fim, os gerentes deveriam escolher somente as alternativas de ação que contribuíssem de maneira decisiva para o lucro geral da empresa. Entre cada alternativa considerada, eles deveriam selecionar aquela que apresentasse maior probabilidade de proporcionar o maior resultado (GITMAN, 2005, p. 12).

Para os acionistas, o lucro é crítico na decisão de investimento. Pode ser medido historicamente e permite comparar os ganhos reais com os níveis esperados. Embora o desempenho 
futuro não seja garantido pelo desempenho passado, esses dados podem fornecer uma base para as expectativas futuras. $\mathrm{Na}$ análise final, é o futuro que importa quanto às decisões de investimento. Portanto, o retorno esperado é uma medida vital de desempenho. É o que o acionista espera ganhar com um investimento que ele está disposto a pagar (GITMAN, JOEHNK, 2005, p. 103).

\section{PROBLEMA DE PESQUISA}

O objetivo desta investigação foi verificar, em um jogo de empresas, sinais de gestão estratégica de mercado e seus efeitos nas empresas estudadas, tais como lucros superiores e maiores retornos para o acionista. A questão basilar indaga se a as decisões planejadas e coordenadas sobre produto, preço, propaganda e distribuição produziram resultados superiores e se sinalizaram a viabilidade do negócio. Neste estudo, foram definidos como indicadores: 1) a tendência de lucratividade de longo prazo coerente e superior ao histórico do setor ; 2 ) o retorno para o acionista através da taxa interna de retorno (TIR). A literatura informa que a gestão estratégica de mercado e as decisões que envolvem o composto mercadológico visam a integrar procedimentos para um negócio rentável (NAGLE, HOLDEN, 2002; DIAS, 2006; URDAN, URDAN, 2006).

Para a consecução do objetivo de pesquisa na gestão simulada, definiu-se um período base (trimestre T1), representado pelo histórico dos investimentos e pelos resultados para a indústria estudada a fim de balizar as análises de decisões dos gestores (Tabela 1). Nesse ambiente, foram tomadas decisões referentes às variáveis do composto de marketing e observado o resultado empresarial.

Tabela 1 - Decisões empresariais e resultados

\begin{tabular}{lll}
\hline Decisões & Variáveis & Histórico (T1) \\
\hline Política de Preços & $\mathrm{CV} *<$ preço $<\$ 9,0$ & $\$ 6,40$ \\
\hline Esforços de MKT & $\begin{array}{l}\text { Gastos em MKT } \\
\text { - propaganda } \\
\text { - comissão de vendas } \\
- \text { distribuicão }\end{array}$ & $\$ 240.000$ \\
\hline Investimento em P\&D & $\begin{array}{l}\text { Efeitos de P\&D } \\
\text { - produto } \\
\text { - processos }\end{array}$ & $\$ 150.000$ \\
\hline $\begin{array}{l}\text { Lucro Líquido } \\
\text { (Resultado alcançado) }\end{array}$ & $\begin{array}{l}\text { - unidades monetárias } \\
\text { \$168.283 }\end{array}$ \\
\hline
\end{tabular}
2007, p. 107):

$$
\mathrm{PLE}_{0}=\frac{\mathrm{D} 1}{(1+\mathrm{r})}+\frac{\mathrm{D} 2}{(1+\mathrm{r})^{2}}+\cdots+\frac{\mathrm{Dn}+\text { PLEn }}{(1+\mathrm{r})^{\mathrm{n}}}
$$

$\mathrm{PLE}_{0}=$ Patrimônio Liquido econômico inicial

$\mathrm{Dn}=$ Dividendos distribuídos no trimestre $\mathrm{n}$

$\mathrm{n}=$ Período trimestral

$r=$ Taxa de retorno procurada 
Foi calculada, ao final de quatro trimestres, a TIR de cada empresa e a TIR média do setor ( $7,3 \%$ ao ano), classificando-se as empresas acima e abaixo da média. Neste estudo, considerou-se curto prazo o trimestre corrente, médio prazo o seguinte e longo prazo os trimestres subsequentes (terceiro em diante).

\section{MÉTODO DE PESQUISA}

Educar profissionais para administrar organizações, capacitando-os para o enfrentamento das responsabilidades e desafios presentes, requer a busca de novos modelos e processos que provoquem a transformação do pensamento gerencial (CLOSS; ANTONELLO, 2010, p. 27). O Laboratório de Gestão (simulador, jogo de empresas e a pesquisa teórico-empírica) tem sido um campo fértil de pesquisa na área de aprendizagem gerencial e no estudo das diferentes estratégias empresariais (SAUAIA, 2008). Simulação é um meio de se experimentar ideias e conceitos sob condições que estariam além das possibilidades de se testar na prática, devido ao custo, à demora ou ao risco envolvidos, caracterizando, de modo abrangente, o significado da palavra simulação (MARTINELLI apud SAUAIA, 1989). As simulações por jogos de empresas, por estabelecerem analogias entre estes e os laboratórios de gestão, podem permitir ao pesquisador controlar tantas variáveis quantas desejar e manipular aquelas julgadas convenientes para a sua experiência (TANABE, 1977).

Segundo Philippatos e Moscato (1971), as escolas de negócios e as empresas ressaltam a aplicação de simulações interativas como um método educacional, denominadas de Jogos de Gerência, Simulação de Negócios e Jogos de Negócios. Essa técnica pedagógica tem sido utilizada para instrução de gerentes e alunos, treinamento, simulações de decisões empresariais, pesquisa e experimentos por grande número de universidades e organizações. Entre todas as aplicações possíveis do jogo de empresa, esses autores sublinham a importância de aplicar o jogo de empresa como instrumento de pesquisa.

Diante do problema de pesquisa proposto, conduziu-se um estudo laboratorial e descritivo. Esse estudo foi assim classificado por ser tratado em ambiente circunscrito ao Laboratório de Gestão - do programa de pós-graduação stricto sensu da Faculdade de Economia, Administração e Ciências Contábeis de uma Instituição de Ensino Superior. É de natureza descritiva por tentar caracterizar o fenômeno de interesse: a gestão de marketing e a lucratividade empresarial. Os sujeitos do experimento foram as empresas simuladas, geridas pelos alunos do curso de mestrado e doutorado da instituição, que atuaram como gestores de suas respectivas empresas simuladas.

\subsection{Descrição do experimento e coleta de dados}

Os gestores das empresas simuladas tomaram decisões para quatro períodos trimestrais nas diversas áreas gerenciais, competindo entre si, num mercado oligopolista, valendo nota para aprovação na disciplina Laboratório de Gestão. Esse mercado é caracterizado por um número relativamente pequeno de participantes, oferecendo um produto padronizado ou diferenciado (MORRIS; MORRIS, 1994, p. 131). As ações de uma empresa individual exercem um impacto perceptivel sobre as outras empresas, caracterizando a interdependência delas (MCGUIGAN e outros, 2004, p. 282). As firmas atuantes nessa simulação comercializam um bem durável multiuso (comunicador, calculadora, relógio, agenda eletrônica e receptor de mensagem), aplicável tanto para residências como para escritórios (SAUAIA, 2007, p. 33).

Para tanto, os tomadores de decisão receberam os relatórios empresariais do período anterior (T1) e um guia prático de gestão com informações sobre o microambiente, o 
macroambiente, as perspectivas, os preços de insumos e a taxa de juros. Esse guia de gestão é fornecido pelo facilitador, que recebe as decisões tomadas a cada período e as processa em um simulador empresarial. Novos relatórios são gerados, iniciando, assim, um novo período decisório. Essa dinâmica se repete por múltiplos períodos, podendo ser realizados vários anos da gestão de uma empresa em apenas algumas horas.

A dinâmica da simulação foi realizada parte dentro do laboratório de gestão e parte fora do mesmo. Durante o Exercício de Gestão Simulada, os gestores prepararam as decisões e avaliaram as possíveis alternativas. Ao final da aula, os dados referentes às decisões foram entregues ao facilitador para processamento. Os relatórios gerados foram disponibilizados para que os gestores avaliassem individualmente os resultados do período antes da rodada seguinte. No inicio da aula seguinte, o facilitador entregou um informativo com um novo cenário a ser trabalhado, juntamente com as folhas de decisão, para que os gestores preparassem um novo conjunto de decisões. Nesse ambiente dinâmico, sujeito à incerteza, os dados para análise das estratégias das empresas foram coletados através dos formulários de decisões e dos relatórios gerenciais das respectivas empresas simuladas num período de quatro trimestres.

\section{ANÁLISE DESCRITIVA DOS DADOS}

A seguir, os resultados deste estudo são apresentados graficamente. A gestão de marketing das empresas simuladas foi analisada considerando o impacto das variáveis do composto de marketing na lucratividade e o retorno para os acionistas por meio da TIR. Com base nesse critério, foram classificadas em dois grupos: as empresas A, C, G e H reproduziram uma gestão de mercado com características mais operacionais, produzindo resultados irregulares e inferiores; as empresas B, D, E, F e I reproduziram uma gestão de mercado com características mais estratégicas, produzindo resultados mais regulares e superiores.

A Figura 1 apresenta as decisões (despesas de MKT e P\&D) e os resultados (Mercado Potencial, Volume de vendas e Lucro líquido) da Empresa A. Esta manteve as despesas de MKT e P\&D para o primeiro trimestre (T2) nos mesmos níveis do histórico do setor (T1). Maiores investimentos em MKT e P\&D no período posterior refletiram demanda e volume de vendas crescentes. Os preços praticados foram $\$ 6,40, \$ 6,00, \$ 7,20, \$ 6,20$ e $\$ 6,10$. Os lucros foram negativos no segundo trimestre (T3) e positivos e constantes nos trimestres subseqüentes, apesar de uma redução nos esforços de MKT e P\&D. A TIR anual foi de 6,89\%.

\section{Empresa A}

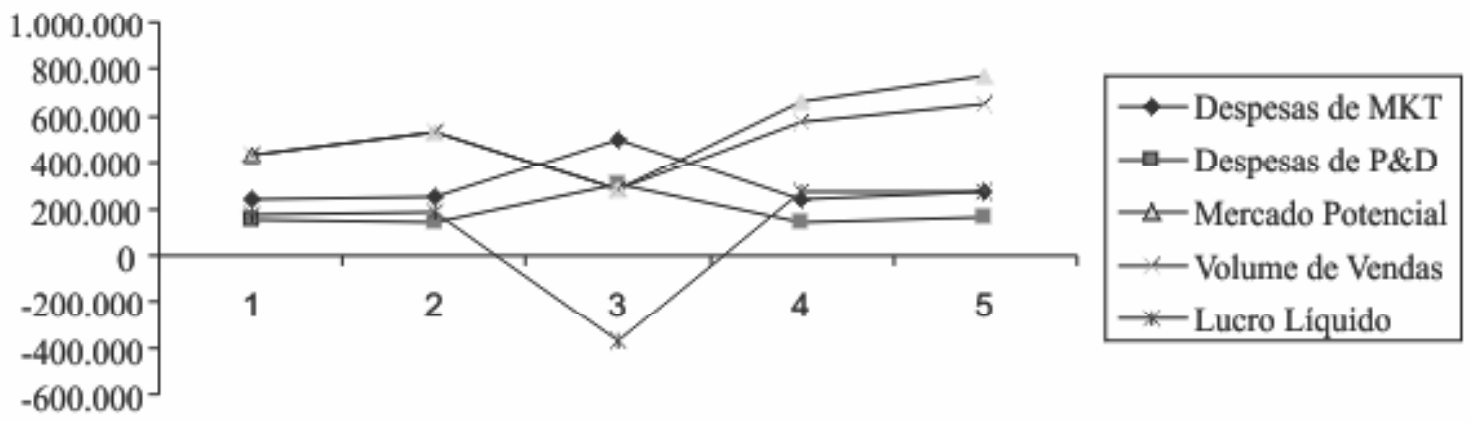

Trimestres

Figura 1 - Decisões e resultados da empresa A 
A Figura 2 mostra as decisões e os resultados da Empresa C. As despesas de MKT foram ligeiramente maiores no primeiro trimestre (T2) e reduzidas acentuadamente no segundo trimestre (T3). No período seguinte (T4), maiores somas foram alocadas, estimulando o mercado potencial e as vendas. Contudo, no último trimestre (T5), foi gerada uma demanda reprimida. As despesas de P\&D foram praticamente constantes até o penúltimo trimestre (T4) e reduzidas subsequentemente. Os preços praticados no período foram de $\$ 6,40, \$ 6,05, \$ 6,05, \$ 5,75$ e $\$ 5,85$ respectivamente. Os lucros apresentaram-se decrescentes até o segundo trimestre (T3), subindo no terceiro trimestre (T4). No último período, a empresa apresentou prejuízos. A TIR anual foi de 3,20\%.

\section{Empresa C}

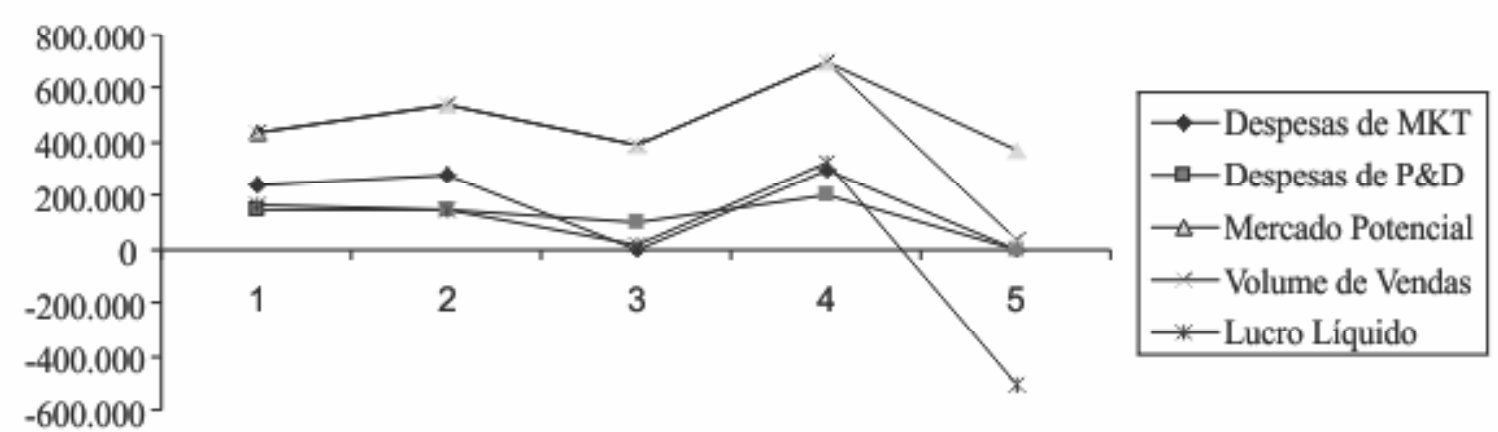

Trimestres

Figura 2 - Decisões e resultados da empresa C

A Figura 3 mostra as decisões e resultados da Empresa G. No primeiro trimestre (T2), os recursos de MKT e P\&D foram maiores do que os do período base (T1). No segundo trimestre (T3), os investimentos de MKT foram ainda de maior monta e os de P\&D reduzidos. As vendas mostramse praticamente constantes com crescimento no quarto trimestre (T5). A empresa tem um grande mercado potencial, porém apresentou demanda reprimida. Os preços praticados foram $\$ 6,40, \$ 6,20$, $\$ 6,15, \$ 6,15$ e $\$ 6,10$. Os lucros apresentaram-se decrescentes, e houve prejuízos no segundo e terceiro trimestres $(T 3, T 4)$, com recuperação no último período (T5). A TIR anual foi de 3,98\%.

\section{Empresa G}

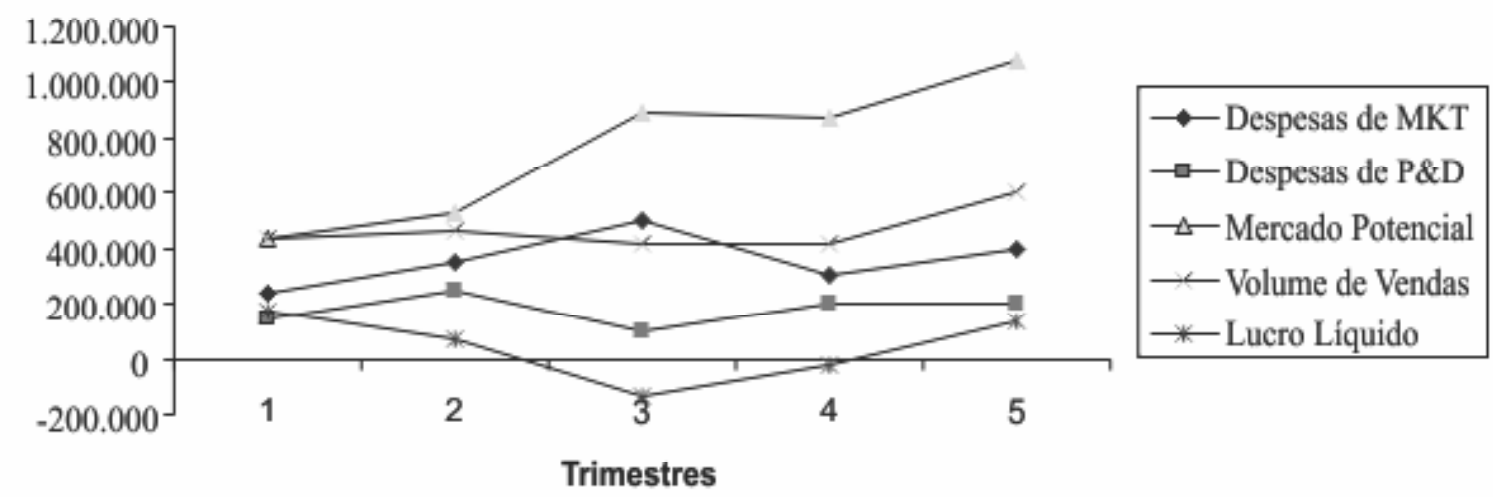

Figura 3 - Decisões e resultados da Empresa G 
A Figura 4 traz as decisões e os resultados da Empresa $\mathrm{H}$. Com investimentos modestos em MKT e P\&D, ao longo dos quatro períodos, e com tendência de decrescimento, os investimentos em $P \& D$ caem à zero no último período. Os preços praticados foram $\$ 6,40, \$ 6,30, \$ 6,42, \$ 6,80$ e $\$ 6,00$. Apesar de o mercado potencial ter sido completamente atendido, os lucros foram decrescentes e negativos no terceiro período (T4) e positivos no quarto trimestre (T5). A TIR anual foi de $4,80 \%$.

\section{Empresa $\mathbf{H}$}

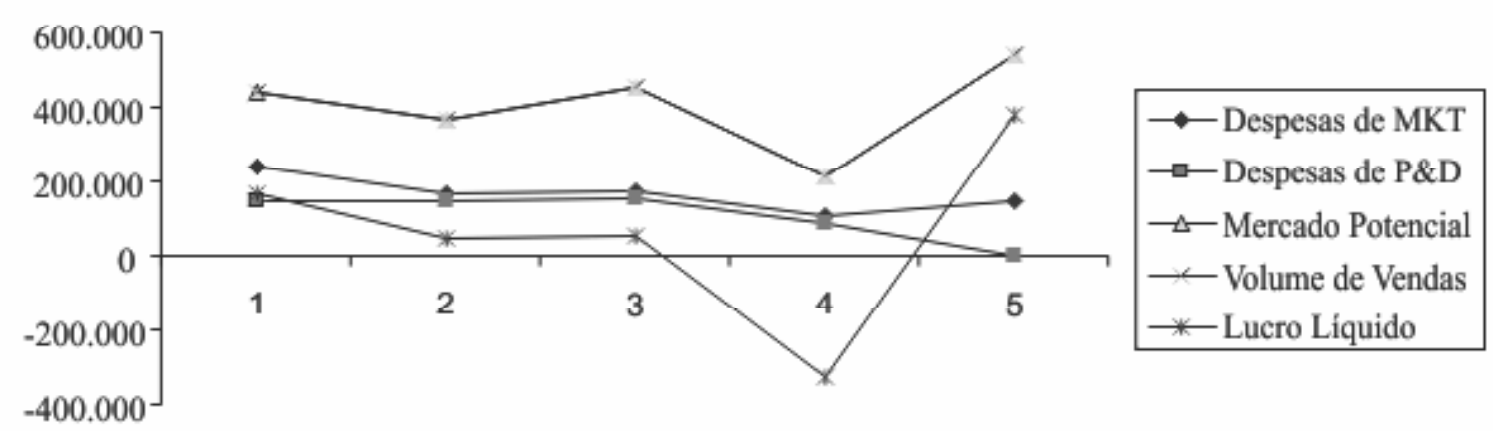

Trimestres

Figura 4 - Decisões e resultados da Empresa $\mathrm{H}$

A Figura 5 expõe as decisões e os resultados da Empresa B. O investimento em P\&D foi o mesmo valor do instante inicial (T1) no primeiro trimestre (T2), de maior monta no segundo trimestre (T3) e decrescente nos períodos subseqüentes. Os preços praticados nesses períodos foram de $\$ 6,40, \$ 5,95, \$ 6,40, \$ 6,70$ e $\$ 6,40$ respectivamente. Os esforços de MKT, apesar de reduzidos no período $\mathrm{T} 3$, resultaram em mercado potencial atendido no primeiro, segundo e terceiro trimestres $(\mathrm{T} 2, \mathrm{~T} 3, \mathrm{~T} 4)$. Os lucros decresceram até o terceiro trimestre, voltando a crescer no último período (T5). A TIR anual foi de 9,31\%.

\section{Empresa B}

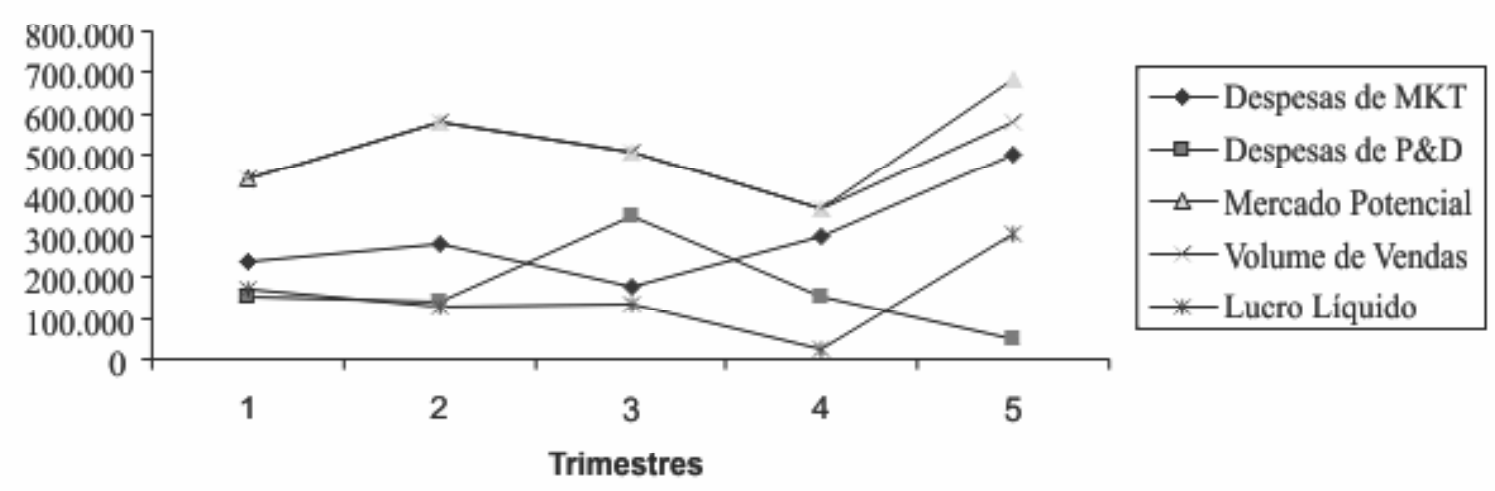

Figura 5 - Decisões e resultados da empresa B

A Figura 6 traz as decisões e resultados da Empresa D. Os investimentos em MKT foram ligeiramente crescentes e os de P\&D constantes no primeiro e segundo trimestres (T2, T3). Essas despesas foram mantidas sem grandes variações, em torno dos patamares do setor. Os preços praticados nos quatro períodos foram $\$ 6,40, \$ 5,90, \$ 5,90, \$ 5,95$ e 5,70 respectivamente. Houve 
demanda reprimida no segundo trimestre (T3), mas atendida nos períodos seguintes. Os lucros mostraram-se sempre positivos e em torno da média do setor. A TIR anual foi de 9,35\%.

\section{Empresa D}

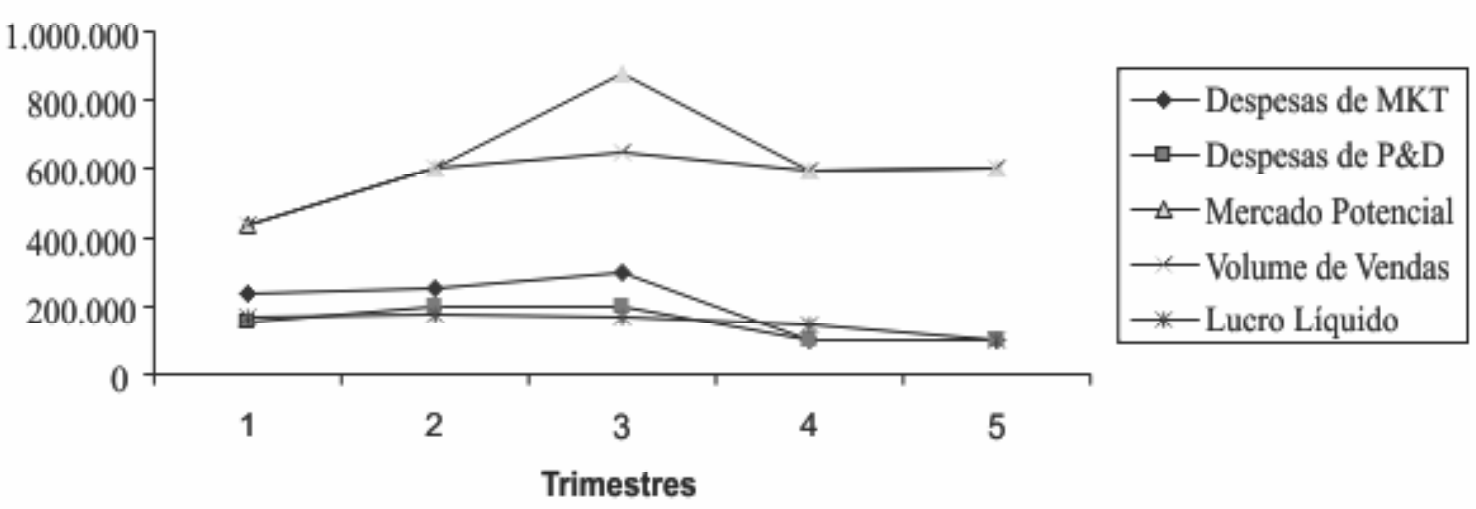

Figura 6 - Decisões e resultados da empresa D

A Figura 7 apresenta as decisões e os resultados da Empresa E. Os investimentos de MKT foram crescentes até o último trimestre. Contrariamente, após o primeiro trimestre (T2), os investimentos de P\&D foram decrescentes. Porém, esses esforços foram mantidos acima da média do setor. Os preços praticados foram $\$ 6,40, \$ 6,40, \$ 6,40, \$ 6,41$ e $\$ 6,50$. Os lucros, o mercado potencial e as vendas seguem crescentes ao longo dos quatro trimestres. A TIR anual foi de $9,69 \%$.

\section{Empresa E}

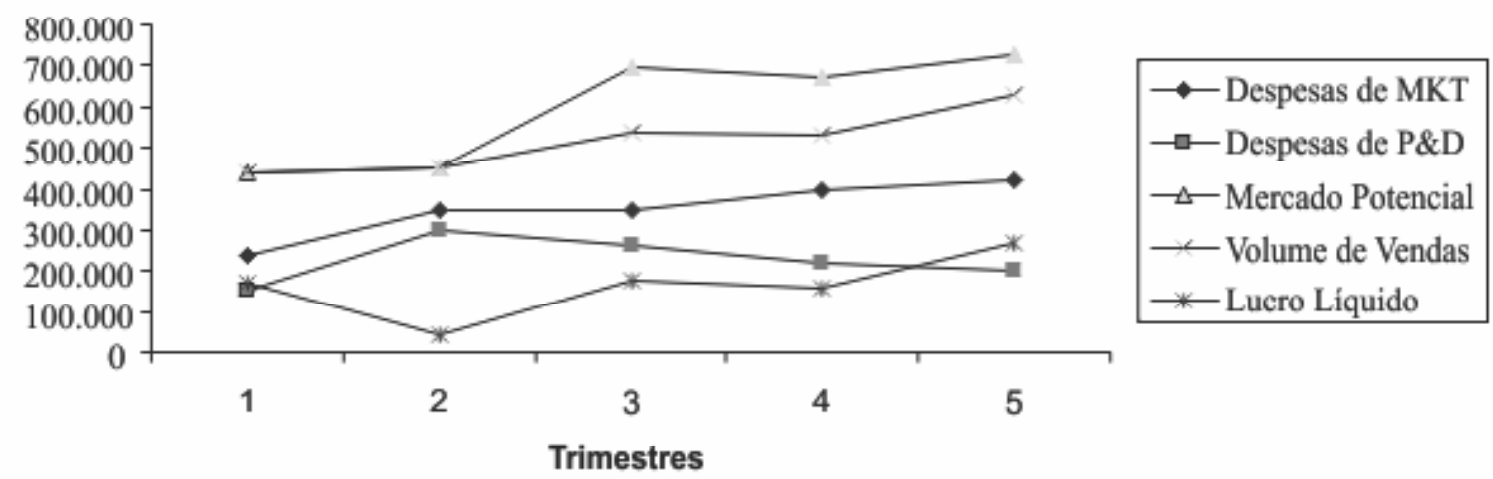

Figura 7 - Decisões e resultados da empresa $E$

A Figura 8 expõe as decisões e resultados da Empresa F. Com investimentos constantes de MKT e P\&D nos três trimestres (T2, T3 e T4), a empresa apresentou lucros positivos depois de um resultado negativo no primeiro período (T2). Houve um crescimento do mercado potencial e das vendas. Os preços praticados foram $\$ 6,40, \$ 6,50, \$ 6,30, \$ 6,00$ e $\$ 6,10$ respectivamente. A lucratividade apresentou queda, juntamente com as vendas, no último trimestre (T5). A TIR anual foi de $8,63 \%$. 


\section{Empresa F}

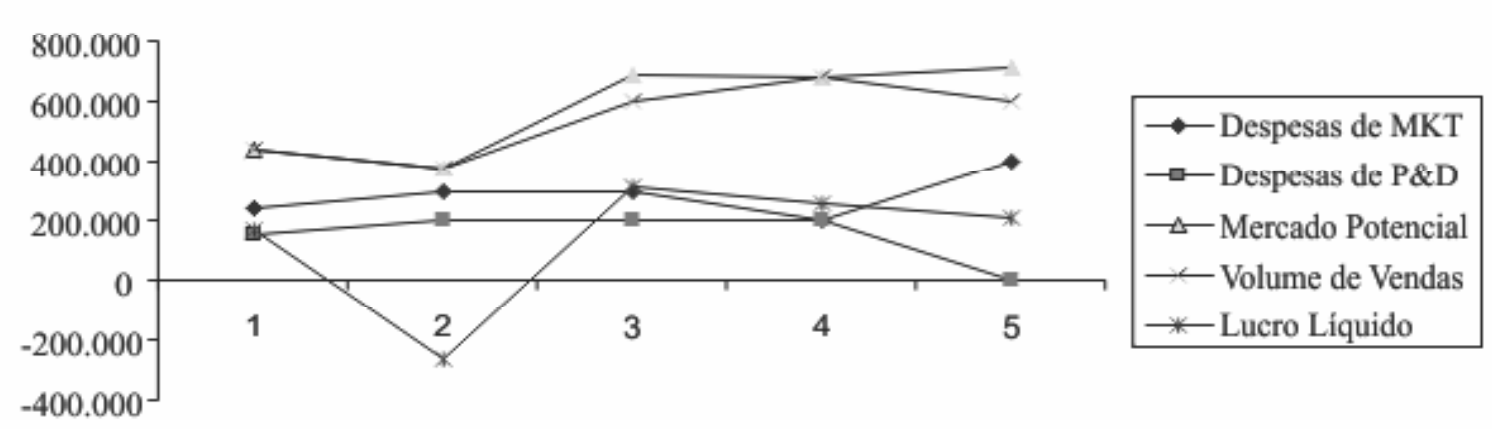

Trimestres

Figura 8 - Decisões e resultados da empresa F

A Figura 9 apresenta as decisões e os resultados da Empresa I. Os esforços de MKT e P\&D foram constantes ao longo dos quatro trimestres. Os preços praticados foram $\$ 6,40, \$ 6,00, \$ 5,98$, $\$ 5,95$ e $\$ 6,01$ respectivamente. Depois de decrescerem no primeiro trimestre (T2), os lucros cresceram no segundo trimestre (T3) e mantiveram-se num patamar acima do padrão do setor. O mercado potencial não é totalmente atendido, contudo, a empresa tem um bom volume de vendas. A TIR anual foi $9,99 \%$.

\section{Empresa I}

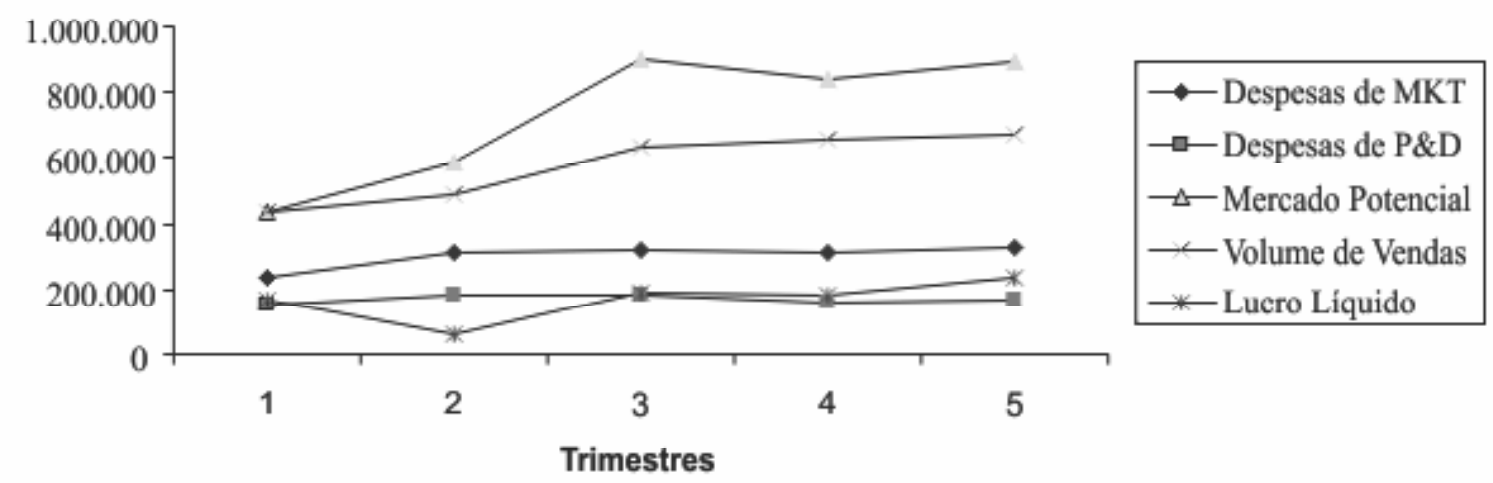

Figura 9 - Decisões e resultados da Empresa I

\section{DISCUSSÃO DOS RESULTADOS}

Nesta seção, examinam-se os resultados à luz do referencial teórico.

As empresas A, C, G e H (Tabela 2) apresentaram prejuízo em algum dos períodos estudados ou lucros abaixo da média anual do setor (\$393.893) e, consequentemente, TIR anual menor que $7,3 \%$ (média da indústria). 0 exame das decisões, irregulares e reativas, sinaliza uma gestão de marketing com características mais operacionais nessas empresas, ou seja, abordagem voluntarista, focada nas oportunidades existentes e nas decisões de curto prazo (LAMBIN, 2000, p. 7-8). A gestão com essa perspectiva de curto prazo foi evidenciada por uma política de preço instável, menores investimentos em P\&D, redução da força de vendas 
e das despesas com propaganda - esforços de MKT (KOTLER; KELLER, 2006, p.17). Os gestores podem ter entendido o ambiente de negócios como pouco sujeito a mudanças, limitando a eficácia de sua estratégia a simples comportamentos de adaptação e reação (AAKER, 1992, p. 12), em lugar de planejamento e antecipação.

Quanto ao composto de mercadológico, as empresas A, C, G e H parecem não ter conseguido um equilíbrio entre o valor para o cliente e, simultaneamente, para o acionista. O equilíbrio desses objetivos é fundamental para a viabilidade empresarial (DIAS, p. 9). Para esse fim, o gerente de marketing deve adequar a oferta da firma e a demanda existente de acordo com as variáveis controláveis produto, preço, comunicação e distribuição (ROCHA; CHRISTENSEN, 1999, p. 26). A discrepância entre esse objetivo foi evidenciada em decorrência de TIR inferior à média do setor (Tabela 2). Um retorno maior que o custo de oportunidade é o que o acionista espera ganhar com um investimento que ele está disposto a realizar (GITMAN; JOEHNK, 2005, p. 103).

Tabela 2 - Empresas com desempenho abaixo da média do setor

\begin{tabular}{cccc}
\hline Empresas & $\begin{array}{c}\text { Investimentos em } \\
\text { MKT e P\&D(\$) }\end{array}$ & Lucro Anual(\$) & TIR Anual (\%) \\
\hline $\mathrm{A}$ & 2.005 .000 & 353.562 & 6,89 \\
\hline $\mathrm{C}$ & 1.030 .000 & -27.530 & 3,20 \\
\hline $\mathrm{G}$ & 2.300 .000 & 53.024 & 3,98 \\
\hline $\mathrm{H}$ & 988.000 & 156.041 & 4,80 \\
\hline Média do grupo & 1.580 .750 & 133.774 & 4,70 \\
\hline
\end{tabular}

Diferentemente, as empresas B, D, E, F e I (Tabela 3) apresentaram, ao longo dos quatro trimestres, lucros positivos, acima da média da indústria (\$393.893), com consequente TIR anual maior que a média 7,3\%. No entanto, cabe ressaltar que apesar de a empresa $F$ ter enfrentado elevado prejuízo no primeiro trimestre, conseguiu melhorar seu desempenho no longo prazo (TIR anual 8,63\%), ainda que inferior às demais. Tal firma adotou, no início, ao contrário das concorrentes, uma política de preços premium $(\$ 6,50)$, desconsiderando a interdependência dos demais atores da indústria que reduziram os preços de um produto inicialmente homogêneo, como alerta McGUIGAN e outros (2004, p. 282). Os fabricantes operaram num mercado com poucos concorrentes e ofereceram produtos inicialmente padronizados e com pequenas variações de preço para diferenciação. Nesse grupo as empresas analisaram a evolução do ambiente de negócios, identificaram produtos-mercados específicos (destinados não necessariamente a todo o mercado potencial, mas a segmentos lucrativos), realizaram maiores investimentos em Marketing e P\&D, atuaram pró-ativamente, voltadas para o longo prazo. Segundo Lambin (2000, p. 9-10), esses aspectos caracterizam uma gestão estratégica de marketing.

No tocante ao composto mercadológico, as empresas $\mathrm{B}, \mathrm{D}, \mathrm{E}, \mathrm{F}$ e I parecem ter conseguido melhor equilíbrio entre o valor para o cliente e para o acionista. Os lucros positivos e a TIR superior à média anual da indústria (Tabela 3) foram decorrentes de demanda criada e atendida de fidelização do consumidor, com políticas previsíveis e regulares. As decisões referentes às variáveis mercadológicas visam a integrar procedimentos para um negócio rentável (NAGLE, HOLDEN, 2002; DIAS, 2006; URDAN, URDAN, 2006). Entre as alternativas consideradas, os gestores devem selecionar aquela que apresenta maior probabilidade de proporcionar o maior resultado (GITMAN, 2005, p. 12). 
Tabela 3 - Empresas com desempenho acima da média do setor

\begin{tabular}{cccc}
\hline Empresas & $\begin{array}{c}\text { Investimentos em } \\
\text { MKT e P\&D (\$) }\end{array}$ & Lucro Anual(\$) & TIR Anual (\%) \\
\hline $\mathrm{B}$ & 1.945 .000 & 593.291 & 9,31 \\
\hline $\mathrm{D}$ & 1.350 .000 & 583.231 & 9,35 \\
\hline $\mathrm{E}$ & 2.500 .000 & 646.844 & 9,69 \\
\hline $\mathrm{F}$ & 1.800 .000 & 507.894 & 8,63 \\
\hline $\mathrm{I}$ & 1.965 .000 & 678.678 & 9,99 \\
\hline Média do grupo & 1.912 .000 & 601.987 & 9,39 \\
\hline
\end{tabular}

\section{CONCLUSÕES}

Diante dos objetivos desta pesquisa, algumas conclusões derivam dos resultados da investigação empírica. Para a tomada de decisões e a implementação de ações mercadológicas que possam assegurar a viabilidade de um negócio, é crucial que profissionais e pesquisadores da área de marketing compreendam como a gestão eficaz de mercado pode ser orientada tal que proporcione viabilidade empresarial.

No ambiente de marketing, o composto mercadológico está no núcleo das decisões. No marketing operacional, a tendência dos profissionais da área era elaborar um composto que maximizasse tão somente a satisfação do cliente, ou o simples aumento da participação de mercado, com foco no volume de vendas, na definição de quotas de mercado, no posicionamento a atingir, e nos meios táticos retirados do composto mercadológico (LAMBIN, 2000 , p. 8). Esforços de marketing utilizados somente para esses fins constantemente resultam em um fluxo de caixa negativo e na impossibilidade de cobrir custos e gerar lucros no longo prazo, preocupação esta do marketing estratégico, evidências observadas no desempenho de quatro empresas estudadas.

O composto de marketing adequado é aquele que equilibra os objetivos dos consumidores e garante a lucratividade para os acionistas da empresa no longo prazo. A continuidade do negócio depende dessa premissa e impõe aos gerentes considerar as vendas e os fluxos de caixa futuros. Embora essa abordagem enfrente os desafios decorrentes da incerteza (DAY, FAHEY, 1998, p.55-56; DOYLE, 2000, p. 64-66), proporciona uma direção objetiva e racional para análise e tomada de decisões (AAKER, 1992, p. 16). Para isso, é preciso analisar as tendências, traçar metas claras e, principalmente, investir decididamente para realizá-las no médio e no longo prazo, em um processo objetivo, controlável, flexível e racional.

Algumas empresas estudadas apresentaram ações operacionais voltadas para o curto prazo, comprometendo, em parte, seus lucros. Outras asseguraram a viabilidade do negócio com lucratividade e com maiores retornos no longo prazo, o que sugere uma orientação mais estratégica para a viabilidade empresarial. Esses resultados indicam que, através de esforços coordenados de marketing, foi possível adequar o composto de mercadológico aos objetivos da empresa e obter resultados lucrativos e sustentáveis.

É nesse contexto que a aplicação de um jogo de empresas revela-se útil, tendo em vista que proporciona aos gestores e pesquisadores um laboratório para testar as diversas possibilidades de decisão e para construir cenários interdependentes, permitindo analisar e compreender as decisões tomadas no período considerado e seus efeitos no futuro (BARÇANTE, 2003, p. 12). 


\section{LIMITAÇÕES E PESQUISAS FUTURAS}

Ainda que a simulação represente uma simplificação, contendo apenas alguns pontos fundamentais da realidade das organizações, os achados em um laboratório de gestão podem ser úteis para a prática de marketing. Estes podem direcionar estratégias específicas, permitindo conhecer seus impactos e custos, norteando os gestores para uma administração mais racional. No entanto, vale ressaltar que o domínio de conceitos e a gestão técnica competente não serão suficientes para assegurar o melhor resultado. A gestão integrada se completa com a comportamental, isto é, com a coordenação do trabalho em equipe, a distribuição de tarefas, a negociação de idéias, o uso do tempo, a liderança, o planejamento e a tomada de decisão em grupo (SAUAIA, 2007, p. 11).

Conforme relatam Closs e Antonello (2010, p.27), educar profissionais para administrar organizações, capacitando-os para o enfrentamento das responsabilidades e desafios presentes, requer a busca de novos modelos e processos, que provoquem a transformação do pensamento e que possibilitem, concomitantemente, o tratamento das dimensões econômica, ética, política, social e ambiental. Assim, o laboratório de gestão oferece um ambiente de pesquisa, reflexão e educação gerencial, que poderá trazer benefícios à academia e às organizações.

Considerando as peculiaridades do exercício de gestão simulada, outras aplicações e pesquisas podem ser recomendadas. Entre os diversos temas pertinentes à gestão e às ciências sociais aplicadas, destacam-se testar conceitos e teorias, planejamento da produção, finanças, gestão interfuncional e seus resultados, avaliação de perfis gerenciais e aprendizagem vivencial. É importante que novos estudos sobre o tema sejam desenvolvidos para comparações e consolidação do corpo de conhecimento acadêmico e profissional brasileiiro. 


\section{REFERÊNCIAS BIBLIOGRÁFICAS}

AAKER, D. A. Strategic marketing Management. 3rd ed. New York: Wiley, 1992.

AMERICAN MARKETING ASSOCIATION. Marketing definitions. USA, August, 2004. Disponível em: http://www.marketingpower. com. Acesso em: 20 nov. 2007.

BARÇANTE, L. C. Jogos de Negócios: revolucionando o aprendizado nas empresas. Rio de Janeiro: Impetetus, 2003.

CHURCHILL, G. A.; PETER, P. J. Marketing: criando valor para o cliente. São Paulo: Saraiva, 2005.

CLOSS, L. S; ANTONELLO, C. S. Aprendizagem transformadora: uma reflexão crítica na formação gerencial. Cadernos EBAPE.BR. v.8, n.1, artigo 2, Rio de Janeiro, Mar, 2010.

COVA, J. G. As conexões entre marketing e a logística na busca do valor ao cliente. Revista Pensamento Contemporâneo em Administração. v.2, p. 42-53, 2008.

DAMODARAN, A. Avaliação de Empresas. 2a ed. São Paulo: Pearson Prentice Hall, 2007.

DAY, G; FANHEY, L. Valuing Marketing Strategies. Journal of Marketing, v.52, Jul, p. 45-57, 1988.

DIAS, S. R. (Org). Gestão de Marketing. São Paulo: Saraiva, 2006.

DINIZ, D. M.; CASTRO, J. M. Processo de gestão estratégica em universidades privadas: um estudo de casos. Revista de Administração. UFSM, Santa Maria, v. 3, n. 3, p. 311-325, set./ dez. 2010.

DOYLE, P. Gerenciamento do Marketing. Baker, J. (Org). Administração de Marketing. Rio de Janeiro, Elsevier, 2005, p. 203-222.
DOYLE, P. Value-Based Marketing: Marketing Strategies for Corporate Growth and Shareholder Value. Wiley, Chichester, 2000.

FERRIS, P. W.; e BENDLE, N. T; PFEIFER, P. E.; REIBSTEIN, D. J. Métricas de Marketing: mais de 50 métricas que todo executivo deve dominar. Porto Alegre: Bookman, 2007.

GITMAN, L. J. Princípios de Administração Financeira. 10a ed. São Paulo: Pearson Addison Wesley, 2004.

GITMAN, L. J.; JOEHNK, M. D. Princípios de Investimentos. 8a ed. São Paulo: Pearson Addison Wesley, 2005.

KOTLER, P.; KELLER, K. L. Administração de Marketing. 12a. ed. São Paulo: Pearson Prentice Hall, 2006.

LAMBIN, J. J. Marketing Estratégico. 4a ed. Portugal: McGraw Hill, 2000.

MCGUIGAN, J. R.; MOYER, R. C.; HARRIS, F. H. B.; Economia de empresas: aplicações, estratégias e táticas. São Paulo: Pioneira Thomson Learning, 2004.

MONROE, K. B. Pricing: making profitable decisions. 3rd ed. McGraw-Hill, 2003

MORRIS, M.; MORRIS, G. Política de preços em um mercado inflacionário. São Paulo: Makron Books, 1994.

NAGLE, T. T.; HOLDEN, R. K. The strategy and tactics of pricing. New Jersey, Prentice Hall, 2002.

ROCHA, A.; CHRISTENSEN, C. Marketing: teoria e prática no Brasil. 2a Ed. São Paulo: Atlas, 1999.

SAUAIA, A. C. A. Gestão da Estratégia: um guia prático (volume 1). Programa de Aprendizagem Vivencial - Grupo de Pesquisas SIMULAB. FEA/ USP/SP. São Paulo, 2007. 
SAUAIA, A. C. A. Laboratório de Gestão: simulador organizacional, jogo de empresas e pesquisa aplicada. Barueri, Manole, 2008.

SAUAIA, A. C. A. Jogos de Empresas: tecnologia e aplicação. 1989. Dissertação de Mestrado, FEA/USP/SP, São Paulo, Brasil.

TANABE, M. Jogos de Negócios. 1977. Dissertação de Mestrado, FEA/USP/SP, São Paulo, Brasil.

URDAN, F. T.; URDAN, A. T. Gestão do Composto de Marketing. São Paulo: Atlas, 2006.

WERNECK, C. L. L; CRUZ, E. P. O uso do "Youtub" como ferramenta de marketing: estudo de caso da Imobiliária Tecnisa. Revista Pensamento Contemporâneo em Administração. $n-8, p$. 1-24, 2009. 